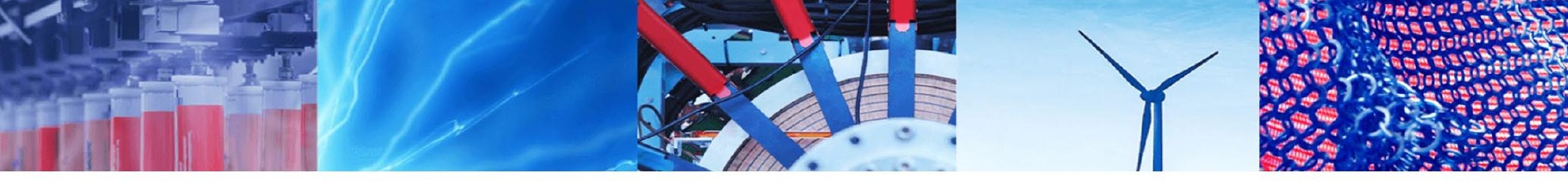

Research Article

\title{
Inhibition of the filamentation of Candida albicans by Borojoa patinoi silver nanoparticles
}

\author{
Marcela Gómez-Garzón ${ }^{1}$ (1) · Luz D. Gutiérrez-Castañeda ${ }^{2}$. Camilo Gil ${ }^{1}$. Carlos H. Escobar ${ }^{1}$. Ana P. Rozo ${ }^{3}$. \\ María E. González ${ }^{3}$ Edgar V. Sierra ${ }^{3}$
}

Received: 1 October 2020 / Accepted: 28 December 2020 / Published online: 25 January 2021

(c) The Author(s) 2021 OPEN

\begin{abstract}
Candida albicans is fungus capable of changing from yeast to filamentous form when it's transformed from a normal commensal to an opportunistic pathogen. The development of alternatives that interfere with this transition could be an effective way to reduce candidiasis. In this regard, evaluate the inhibitory effect of two Borojoa patinoi silver nanoparticles (AgNPs) produced by green synthesis at $5^{\circ} \mathrm{C}$ and $25^{\circ} \mathrm{C}$ on the process of filamentation of Candida albicans. The percentage of inhibition of filamentous forms of C. albicans ATCC10231 and C. albicans SC5314 with AgNPs was determined. Results showed that temperature of synthesis affected both the shape and size of silver nanoparticles synthesized using Borojoa patinoi extracts. The inhibition percentage of filamentous forms of Candida albicans ATCC10231 when treated with silver nanoparticles synthesized at $5^{\circ} \mathrm{C}$ was $85.9 \%$ and at $25^{\circ} \mathrm{C}$ it was $40 \%$. C. albicans SC5314 when treated with AgNP synthesized at $5{ }^{\circ} \mathrm{C}$ was $97.2 \%$ and at $25^{\circ} \mathrm{C}$ it was $64 \%$. Cell toxicity assay showed that at $100 \mathrm{ng} / \mathrm{ml}$, AgNPs synthesized at $25^{\circ} \mathrm{C}$ were safe in MES-OV CRL-3272 cell line. Our results showed that the silver nanoparticles obtained from Borojoa patinoi are inhibitors of the filamentous process of $C$. albicans.
\end{abstract}

Keywords Filamentation $\cdot$ Candida albicans $\cdot$ Silver nanoparticles $\cdot$ Borojoa patinoi

\section{Introduction}

Candida albicans is a polymorphic fungus, capable of developing reversible morphological changes, between yeast and filamentous form. This form is acquired when it's transformed from a normal commensal to an opportunistic pathogen. The development of alternatives that interfere with this transition could be an effective way to reduce candidiasis, including those related with the super infection of medical devices Arkowitz and Bassilana [2].

There are several reports of the antiseptic capability of metal nanoparticles, including those made with silver [39]; Gordienko, Palchikova et al. [8]. However, the nanoparticle synthesis must be optimized to make them secure for humans Mathur, Jha et al. [20]; Souza, da Silva et al. [32].

The bottom up procedure for nanoparticles synthesis, consist of forming metal agglomerates by chemical reducing metal inorganic ions (gold, silver, iron and metal oxides). Recently have it been proposed that these nanoparticles could be produced harnessing the reducing capacities of metabolites and proteins in biological systems, known as green synthesis. The green synthesis of silver nanoparticles using different biological systems (including viruses, bacteria, fungus and plants), has the advantages of being a simple, safe and low cost Nasrollahzadeh, Mahmoudi-Gom Yek et al. [22]. The nanoparticles produced through the green synthesis have been

\footnotetext{
$\triangle$ Marcela Gómez-Garzón, mgomez@fucsalud.edu.co| ${ }^{1}$ Ciencias Básicas. Fundación Universitaria de Ciencias de la Salud, Bogotá, Colombia. ${ }^{2}$ Grupo Ciencias Básicas en Salud, Instituto de Investigación, Fundación Universitaria de Ciencias de la Salud, Bogotá, Colombia. ${ }^{3}$ Facultad de Ingeniería y Ciencias Básicas, Universidad Central, Bogotá, Colombia.
} 
proved to have fungicidal action and control of biofilm formation by Candida albicans Khatoon, Sharma et al. [13].

Plants, such as Borojoa patinoi (borojo), are able to reduce inorganic ions in metallic nanoparticles both in intra and extracellular compartments Rajeshkumar and Bharath [28]. Moreover the plant extracts have a broad spectrum of chemical components that facilitate the bioreduction and stabilization of nanoparticles, conferring it antibactericidal capabilities (Escarcega-Gonzalez, GarzaCervantes et al. [5]; Nasrollahzadeh, Mahmoudi-Gom Yek et al. [22]; Ali, Ikram et al. [1].

The Borojoa patinoi is a fruit native to Colombia, it belongs to the Rubiaceae family and is known for its energy and nutritional capacity. The fruit has high concentrations of amino acids and phosphorus essential for humans. It is used in traditional and popular medicine as a diuretic, healing, aphrodisiac, antimicrobial and antitumor Giraldo, Rengifo et al. [7]; Sotelo D, Casas F et al. [31]

The purpose of this work was to evaluate the inhibitory effect of silver nanoparticles of Borojoa patinoi produced at $5{ }^{\circ} \mathrm{C}$ and $25^{\circ} \mathrm{C}$ on the process of filamentation of Candida albicans. We hypothesized that the synthesis temperature of nanoparticles affects their characteristics and antimicrobial effects.

\section{Experimental details}

\subsection{Materials}

Commercial extract of Borojoa patinoi was provided by Phitother Laboratories. Silver nitrate (AgNO3) was acquired from Panreac (> 99\%) and the distilled / deionized water was obtained from an EasyPure Rodi Ultrapure water purification system with a resistivity higher than $18.2 \mathrm{M} \Omega . \mathrm{cm}$. The solvents used in the rinsing of the nanoparticles and the preparation of the microscopy samples were $96 \%$ ethanol, in addition to the 1-propanol Reagent ACS $\geq 99.5 \%$ were procured from Sigma Aldrich. For the microbiological tests, Sabouraud Dextroxa Oxoid Agar, YPD medium and Trypticase soy broth (Merck), Rabbit Plasma with EDTA (BBL Microbiology Systems) and Calcofluor white dye (Sigma Aldrich) were used. Cytotoxicity was evaluated by using Mc Coy 5 A culture medium (Sigma- Aldrich ${ }^{\circledR}$ ) fetal bovine serum (FBS), 3- (4,5-dimetiltiazol-2-il) -2,5-difeniltetrazolio bromuro (MTT) by Trevigen ${ }^{\oplus}$ and dimethylsulfoxide (DMSO)

\subsection{Preparation and characterization of silver nanoparticles}

AgNPs were obtained by green synthesis from Borojoa patinoi extract. Briefly, they were prepared by mixing 10
$\mathrm{mM} \mathrm{AgNO3}$ in Borojoa patinoi extract at $2 \% \mathrm{w} / \mathrm{v}$. A reaction product was carried out at $5^{\circ} \mathrm{C}$ (AgNPs-43) or at $25^{\circ} \mathrm{C}$ (AgNPs-31), in darkness until day 58.

The reduction of silver ions was confirmed by the color change from yellow to red-brown. The UV-vis spectra of the reaction mixture were periodically measured in a Thermo Scientific Genesys 10 UV-Vis Spectrometer between 200 and $1100 \mathrm{~nm}$, operated at a resolution of $3 \mathrm{~nm}$.

The washes were performed by centrifugation for 30 minutes at 10,000 rpm to purify the AgNPs. The sediment was dispersed in deionized water to remove the watersoluble biomolecules. The samples were dried in an oven at $60^{\circ} \mathrm{C}$ for $24 \mathrm{~h}$.

The hydrodynamic size of the particles and the polydispersity index (PDI) of the silver nanoparticles were analyzed by means Dynamic Light Scattering (DLS) (Malvern Zetasizer Nano ZS90 Dynamic Light Scattering). The analysis of the samples was carried out in aqueous solution at a controlled temperature. The product of the synthesis was quantified by determining the weight of the sample on a dry petri dish: a previously homogenized 2 $\mathrm{ml}$ aliquot was taken, once these solutions were dried and cooled the AgNP's mass was calculated. The shape of the nanoparticles was determined by Transmission Electron Microscopy (TEM) and size measurements of the images were obtained using the ImageJ / Fiji 1 image processor.

\section{Strains of Candida albicans}

Two reference strains of Candida albicans from American Type Culture Collection (ATCC), C. albicans ATCC10231 and C. albicans SC5314 / ATCCMYA-2876 were tested. The strains were cultivated in Sabouraud Dextroxa Agar overnight at $37^{\circ} \mathrm{C}$. Candida cells were grown overnight in YPD medium ( $1 \%$ yeast extract, $2 \%$ peptone and $2 \%$ dextrose), the yeast concentration was adjusted spectrophotometrically to absorbance of 0.12 corresponding to $1 \times 10^{6}$ yeast/ $\mathrm{ml}$.

The effect of nanoparticles on the transition to filamentous form, the inhibitory effect of AgNPs-31 and AgNPs-43, was tested with the two strains of $C$. albicans as follows: $50 \mu \mathrm{L}$ of $1 \times 10^{6}$ yeast $/ \mathrm{ml}, 75 \mu \mathrm{L}$ Trypticase-Soy broth, $50 \mu \mathrm{L}$ of Rabbit Plasma with EDTA, $25 \mu \mathrm{L}$ of AgNPs at $100 \mu \mathrm{g} / \mathrm{ml}$, and $10 \mu \mathrm{l}$ of Calcofluor white were mixed and incubated at $37^{\circ} \mathrm{C}$ for $4 \mathrm{~h}$. Each nanoparticle was evaluated in duplicates. For the positive control of filamentation, $50 \mu \mathrm{L}$ of $1 \times 10^{6}$ yeast $/ \mathrm{ml}, 75 \mu \mathrm{L}$ Trypticase-Soy broth, $50 \mu \mathrm{L}$ of Rabbit Plasma with EDTA and $10 \mu$ l of Calcofluor white were used. Quantification of inhibition of the budded-to-hyphal-form transition was accomplished by counting the number of individual budded cells versus the number of filamentous 
form in the population. More than 100 cells were counted for each well in duplicate, and all assays were repeated at least twice Toenjes, Munsee et al. [35]; Romo, Pierce et al. [29]. Additionally, images of the cell morphology were obtained under a Leica DM 2500 microscope under fluorescence with the UV filter A (Exc: 340-380 / EspDic: 400 / Bar: 430), where the yeasts were observed stained silver blue.

\section{Cell culture}

The MES-OV CRL-3272 ${ }^{\text {TM }}$ cell line was obtained from ATCC ${ }^{\oplus}$ (American Type Culture Collection). The cell line were cultured in Corning Glass Culture Flasks from Sigma-Aldrich ه and cultured in McCoy 5A medium supplemented with $10 \% \mathrm{SFB}(\mathrm{v} / \mathrm{v})$, and cultures were maintained at $37^{\circ} \mathrm{C}$, in a humid atmosphere containing $5 \% \mathrm{CO}_{2}$.

\section{Cell viability}

The cytotoxic induced by nanoparticles was evaluated through the mitochondrial activity of cells incubated with AgNPs using the MTT assay. Fifty $\mathrm{ng} / \mathrm{mL}$ or $100 \mathrm{ng} /$ $\mathrm{mL}$ of nanoparticle were dissolved in Mc Coy $5 \mathrm{~A}$ medium and sonicated by 10 min using ultrasonicator Elmasonic $\mathrm{S} 30$. Then, $5 \times 10^{5} \mathrm{MES}-\mathrm{OV}$ cells were incubated with $50 \mathrm{ng} /$ $\mathrm{mL}$ or $100 \mathrm{ng} / \mathrm{mL}$ the AgNPs for 24,48 and $72 \mathrm{~h}$ at $37^{\circ} \mathrm{C}$, in a humidified $5 \% \mathrm{CO}_{2}$. The results were compared with effect of commercial nanoparticles (AgNPs, Sigma-Aldrich reference 730793 , size of $20 \mathrm{~nm}$ ). MTT assay was realized after indicated times. Each cell group adding tetrazolium salt (MTT reagent) and dark-incubated at $37{ }^{\circ} \mathrm{C}$ for $4 \mathrm{~h}$. Formazan crystals generated by metabolically active cells were solubilized with detergent reagent and incubated for $4 \mathrm{~h}$ at $37^{\circ} \mathrm{C}$. Absorbance was read in a microplate reader at $650 \mathrm{~nm}$ (Ultramark microplate reader. Model 8422, BioRad). Cells without nanoparticles were used as control. Data were expressed as the percent SD of metabolic activity with respect to the non-inoculated controls using the following formula: (OD well of cells incubated with AgNPs $(-$ blank $)) /($ mean OD non-inoculated cells well (-blank)) $\times 100$.

\section{Statistic evaluation}

Experiments of filamentation were performed in duplicate. Experiments of cytotoxicity were performed by triplicate. The results were reported as mean and standard deviation. The statistical analysis was performed by descriptive statistics using frequencies and percentages using STATA (Version 15.0. Texas, StataCorp LLC)

\section{Results and discussion}

AgNPs were obtained through the reduction of silver ions added to the extract of the plant. Color change from yellow to red-brown indicated the formation of AgNPs. The formation and stability of the nanoparticles were evaluated by UV-Vis spectrophotometric analysis. The reaction progression upon formation of the AgNPs-31, synthesized at $25^{\circ} \mathrm{C}$, and AgNPs-43, synthesized at $5{ }^{\circ} \mathrm{C}$, is shown in Fig. 1, with a peak occurring between 400 and $500 \mathrm{~nm}$.
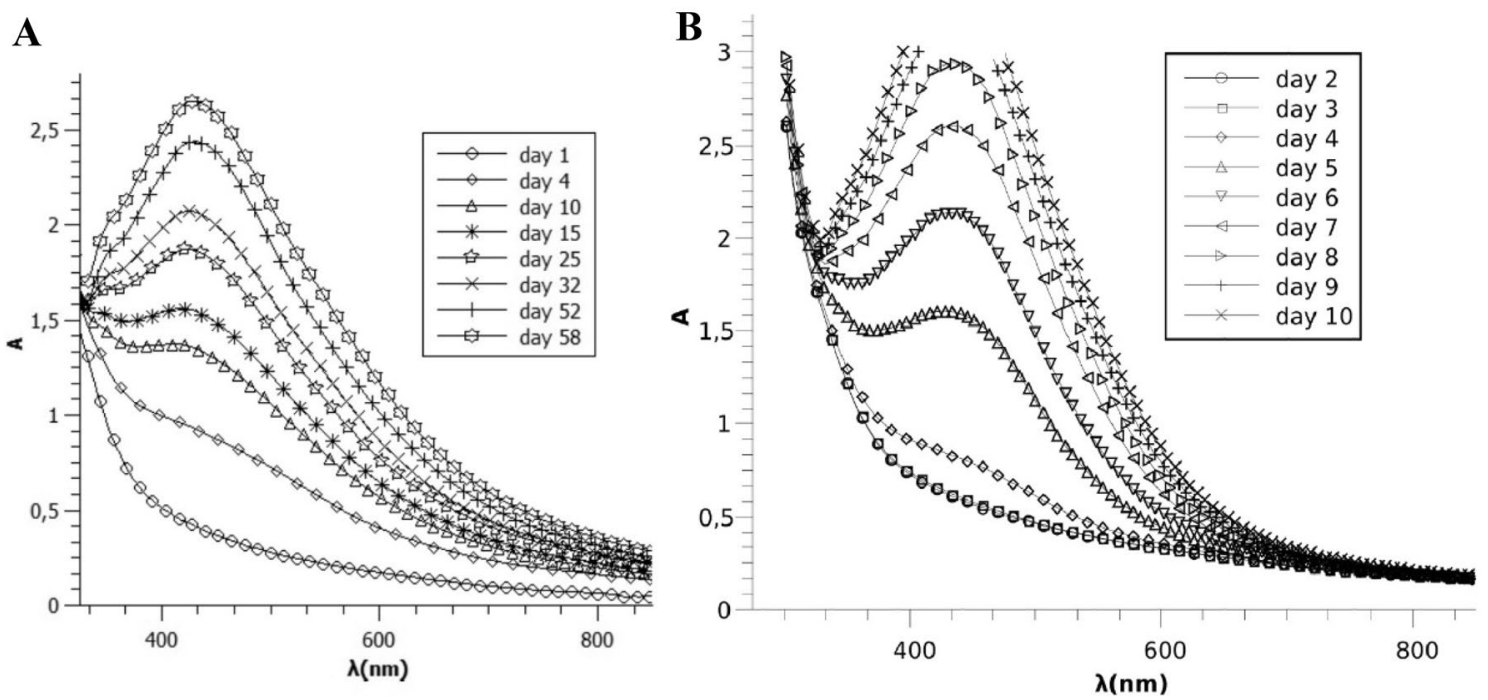

Fig. 1 The reaction progression upon formation: a AgNPs-31 synthesized at $25^{\circ} \mathrm{C}$ and $\mathbf{b}$ AgNPs- 43 , synthesized at $5{ }^{\circ} \mathrm{C}$ 
The formation of nanoparticles due to the reduction of AgNO3 during incubation with Borojoa patinoi extract is evident by the change in the color of the reaction mixture, which turned from yellow to red-brown. During the process of green synthesis, the brown color is due to the excitation in the absorption spectrum of the plasmon vibrations of the surface of the plant extracts at different wavelengths, ranging from 300 to $700 \mathrm{~nm}$ generally with a peak at $435 \mathrm{Ghareib}$, Tahon et al. [6]. The surface plasmon resonance band is influenced by the size, shape, morphology, composition and dielectric environment in the synthesized nanoparticles Chahardoli, Karimi et al. [4].

In the DLS size distribution of the AgNPs-31, a peak of $213.2 \mathrm{~d}$.mn with an intensity of $95.9 \%$ was observed, a second peak of $4544 \mathrm{~d}$.nm with an intensity of $2.6 \%$ and a third peak of $10.5 \mathrm{~d}$.nm with intensity of $1.5 \%$. For the AgNPs-43 the first peak of $238.7 \mathrm{~d}$.mn with intensity of $92.9 \%$, a second peak of $22.64 \mathrm{~d}$.nm with intensity of $5.2 \%$ and a third peak of $4734 \mathrm{~d} . \mathrm{nm}$ and intensity of $1.8 \%$ (Fig. 2). The differences in the average hydrodynamic diameter and in the polydispersity index (Pdl) were established according to the temperature change (Fig. 3). The final concentration of the nanoparticles obtained by green synthesis was $275 \mu \mathrm{g} / \mathrm{ml}$ for AgNPs-31 and $150 \mu \mathrm{g} / \mathrm{ml}$ for AgNPs-43.

The AgNPs rate formation was related to the reaction temperature such that an increase in the temperature allowed the production of particles at a faster rate. The peak absorption of $435 \mathrm{~nm}$ indicating the formation of AgNPs, confirmed by the slight change in the maximum of the absorption spectra indicating that the silver had been completely reduced, was reached in 8 days at $5^{\circ} \mathrm{C}$ but took 52 days at $25^{\circ} \mathrm{C}$; additionally a higher concentration was obtained at $25^{\circ} \mathrm{C}(275 \mu \mathrm{g} / \mathrm{ml})$.

The trimodal distribution of the AgNPs were obtained by DLS. The area under the curve indicated that the highest proportion of particles were of large diameters: 213.2 $\mathrm{nm}$ for AgNPs-31 and $238.7 \mathrm{~nm}$ for AgNPs-43. Only 1.5\%

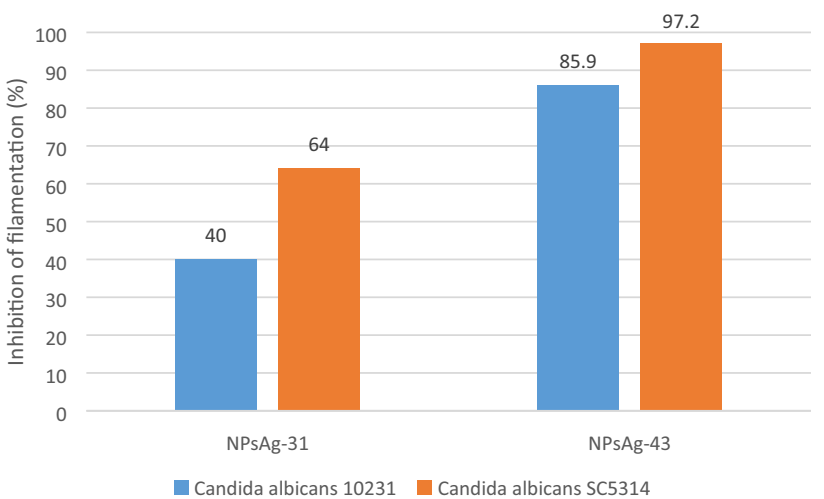

Fig. 3 The differences in the average hydrodynamic diameter (d.nm) and in the polydispersity index (Pdl) according to the temperature change

of the AgNPs-31 corresponded to particles of small size $(10.5 \mathrm{~nm})$, while the rest corresponded to the large size. According to the polydispersity index (PDI) of all the experiments (greater than 0.1) we found that polydispersed solutions were synthesized.

The morphology, size and shape were determined by TEM.AgNPs-31 were spherical shapes of $18-45 \mathrm{~nm}$ and rods of $31-38 \mathrm{~nm}$ in width by $50-75 \mathrm{~nm}$ length. AgNPs-43 were only spherical shapes of 20.6-330nm (Fig. 4).

The characterization of the samples by TEM demonstrated the presence for AgNPs-31 of spherical shapes of $18-45 \mathrm{~nm}$ and rods with $31-38$ in width by $50-75$ in length for AgNPs-31 and only spherical shapes of 20,6-330nm for AgNPs-43. Similar geometries were previously reported in other silver nanoparticles synthesized by green synthesis Ma, Su et al. [19]; Taha, Hawar et al. [33].

The nanoparticles show mechanisms of fungicidal action different from traditional antifungals, thus providing an alternative to the growing resistance Chahardoli, Karimi et al. [4]. The NPs can cross the cell membrane and reach the intracellular space, where they generate a large
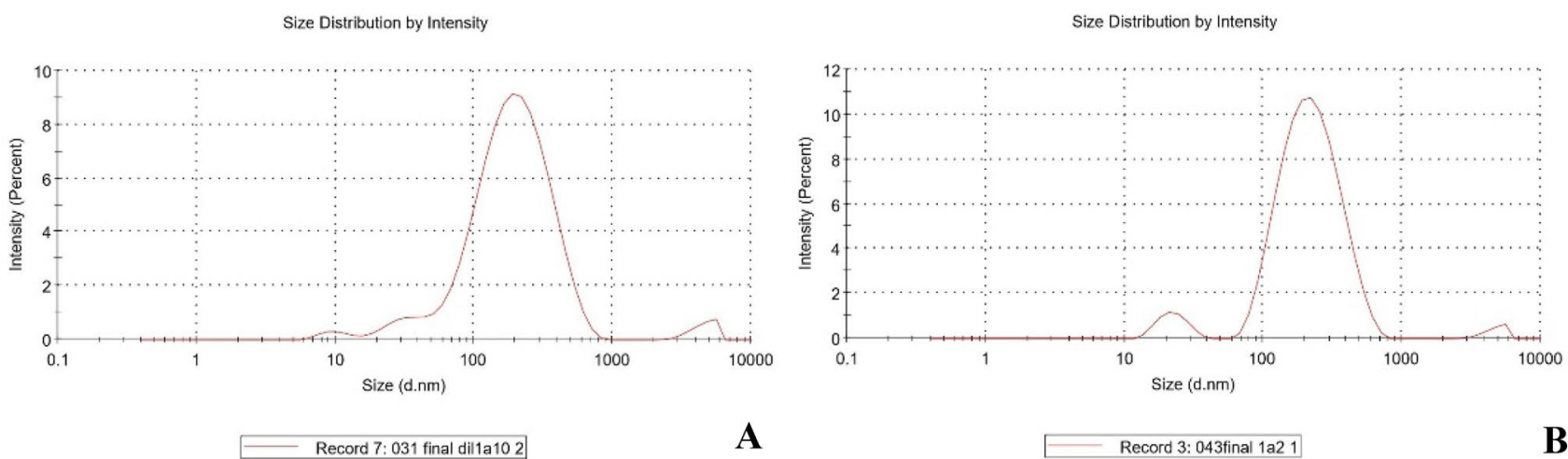

Fig. 2 Dynamic Light Scattering (DLS) size distribution of the a AgNPs-31 and b AgNPs-43

\section{SN Applied Sciences}


Fig. 4 Representative Transmission Electron Microscopy (TEM) micrographs for the a AgNPs-31 and b AgNPs-43

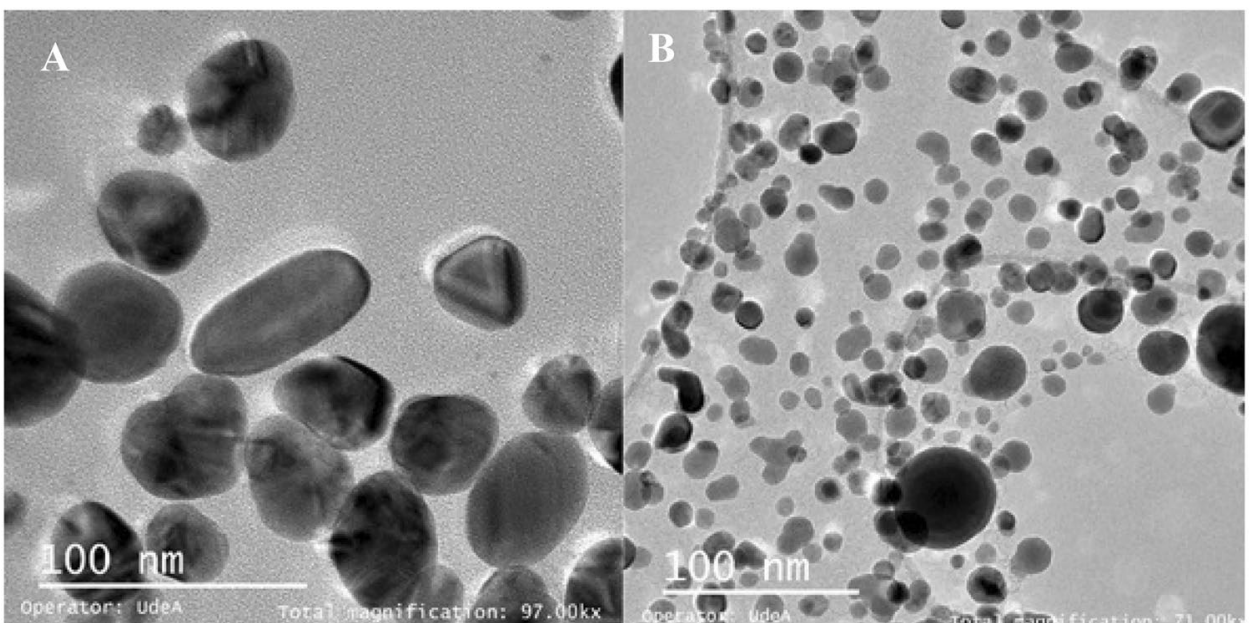

oxidative imbalance by raising the levels of reactive oxygen species (ROS). Large ROS imbalance can degrade the essential components of the cells responsible for maintaining the physiological and morphological functions of the cells. ROS cause damage at the membrane and DNA level, leading to the death of the fungus Wang, Hu et al. [38]; Uddin, Siddique et al. [36].

The effect of AgNPs-31 and AgNPs-43 on C. albicans ATCC 10231 and C. albicans SC5314 was determined by the percentage of inhibition of filamentation. The result revealed that C. albicans SC5314 presented $64 \%$ with AgNPs-31 and $97.2 \%$ with AgNPs-43 (average $80.6 \%$ ), while C. albicans ATCC 10231 40\% with AgNPs-31 and 85.9\% with AgNPs-43 (average 63.0\%) (Fig. 5). The filamentation

Fig. 5 Inhibition of filamentation of AgNPs-31 and AgNPs-43 on C. albicans ATCC 10231 and C. albicans SC 5314
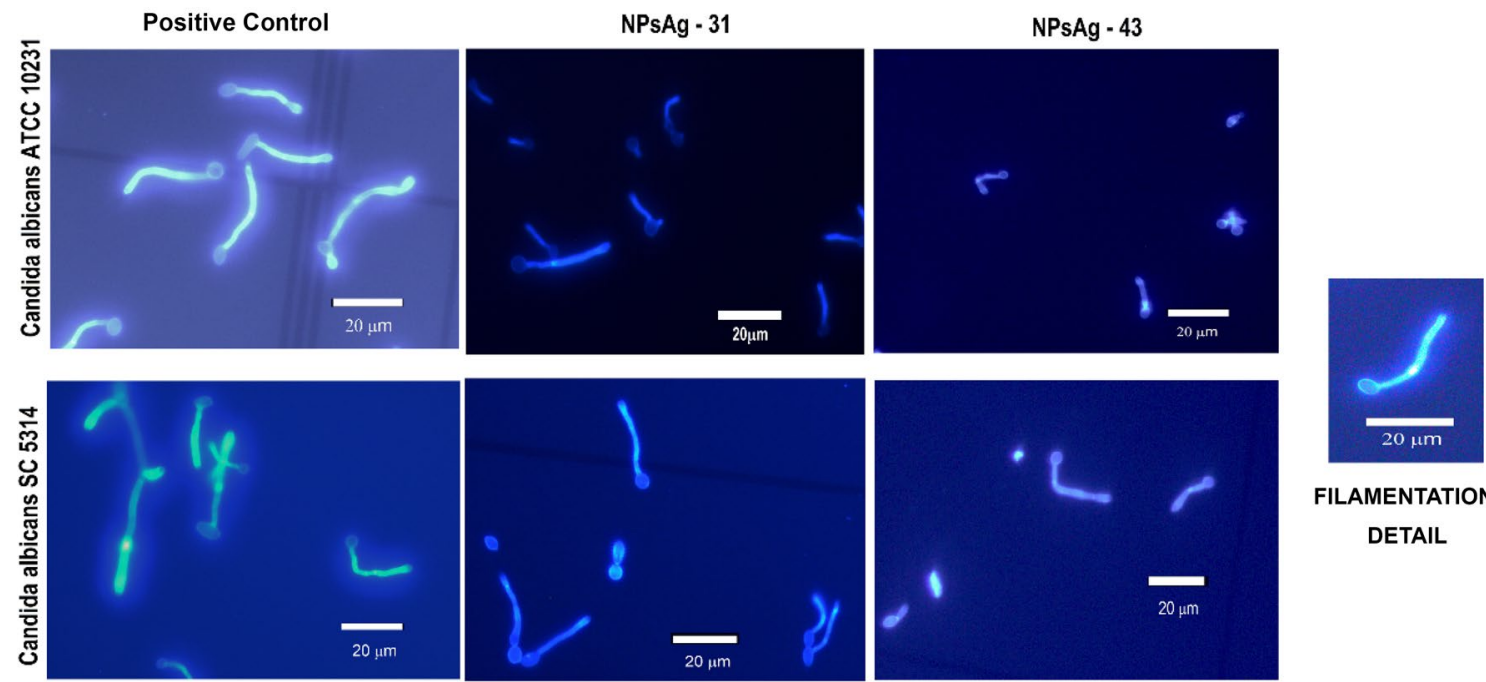

FILAMENTATION DETAIL

Fig. 6 The filamentation morphology of positive controls, NPsAg-31 and NPsAg-43 of both Candida albicans SC 5314 and ATCC 10231 , using fluorescence with Calcofluor white 
morphology was documented under fluorescence with Calcofluor white (Fig. 6).

The two clinical isolates SC5314 and ATCC10231 of C. albicans both differ in their ability to invade host tissue and cause experimental infections. Strain SC5314 was isolated in 1984 from a candidemia patient and is considered a reference of the invasive strain (Odds, Brown et al. [24]. Meanwhile the strain ATCC10231 is strongly attenuated in virulence due to gene duplication or loss of an allele (hewes, Moran et al. [34]. When comparing the two species of Candida albicans, we observed that $C$. albicans SC5314 was more sensitive to both AgNPs than C. albicans ATCC10231, resulting in a higher percentage of inhibition of filamentous forms necessary to initiate an invasive process ( $80.6 \%$ vs $63.0 \%$ respectively). Strain ATCC 10231 is frequently used for pharmacological purposes, although several studies have shown that this strain produces shorter germ tubes compared to strain SC5314 Thewes, Moran et al. [34]; Romo, Pierce et al. [29]; Bartelli, Bruno et al. [3]. Our results suggest that NPsAg interfered with the CAMPPKA and MAPK pathways, which are widely employed by fungal pathogens to control the morphological transition Meng, Zhao et al. [21].

The microscopic evaluation of the yeasts with Calcofluor White, allowed us to observe the inhibitory effect of the AgNPs. Scarce filamentation and predominance of blastoconidia was seen in Fig. 6. The effectiveness of AgNPs against C. albicans has been shown to be due to morphological changes in fungal cells, damage to the membrane, formation of pores that cause the release of ions and induced alterations in multiple cellular targets Wady, Machado et al. [37]; Radhakrishnan, Reddy Mudiam et al. [26]. In a study with SEM, it was observed that the structure of $C$. albicans was lost when treated with AgNPs, due to the rupture of the membrane and cell wall; additionally, this study showed inhibition of filamentation. Using TEM it was shown that there was a change in the permeabilization of the cell wall and subsequent explosion of the inner layers of the fungal wall Lara, Romero-Urbina et al. [17].

Several studies have shown that AgNPs synthesized by physical or chemical routes have the potential to induce toxicity to cells of animals. Nanoparticles absorbed to an external surface of organisms, however, can in some cases damage cell walls or cell membranes or cause a steady release of ions that affect the cell Liu, Wu et al. [18]; Newton, Puppala et al. [23]; Seitz, Rosenfeldt et al. [30]; Hu, Chen et al. [10]. The average viability of cells treated with AgNPs-31 in $50 \mathrm{ng} / \mathrm{mL}$ and $100 \mathrm{ng} / \mathrm{mL}$ concentrations varied between 57 and $86 \%$ at 24,48 and $72 \mathrm{~h}$. This viability was similar to observed with the AgNPs Sigma-Aldrich ${ }^{\circledast}$. The AgNPs-43 in $50 \mathrm{ng} / \mathrm{mL}$ and $100 \mathrm{ng} / \mathrm{mL}$ concentrations generated viability between 29 and 43\% (Fig. 7). These results show that the sizes of the nanoparticles are determinants of the degree of cytotoxicity. How it was observed the larger particles (AgNPs-43) induced a greater cytotoxic effect, decreasing viability by more than $50 \%$ on average independent of incubation time and concentration. Likewise, the results shown here indicate that AgNP-31 are less toxic at concentrations of $50 \mathrm{ng} / \mathrm{mL}$ up to $100 \mathrm{ng} / \mathrm{mL}$. This effect in the cell viability may be particularly important for clinical application.

The average toxicity against the cell line MES-OV CRL-3272 of AgNPs-31 at concentrations of $50 \mathrm{ng} / \mathrm{ml}$
Fig. 7 Cells viability of treatments with different concentrations of Ag-NPs-31 and AgNPs-43 after 12, 24 and 48hs

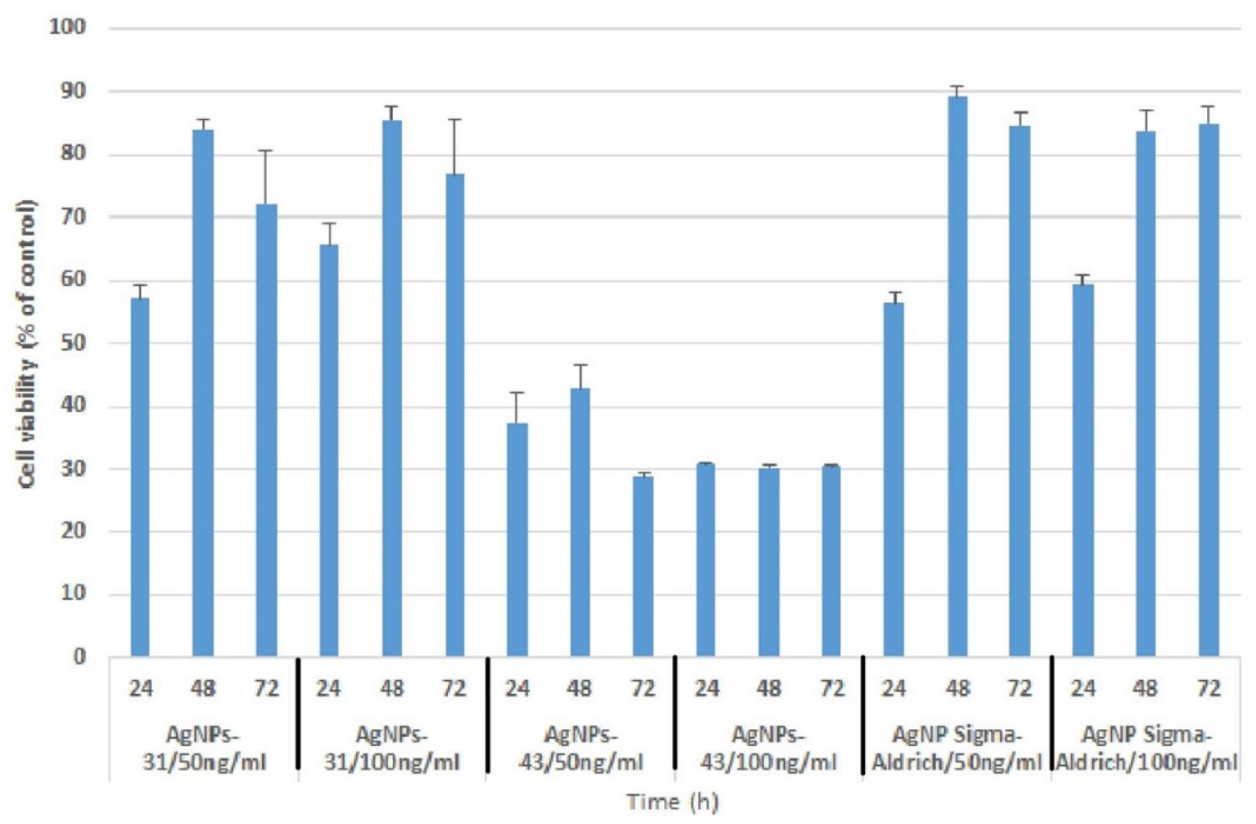


and $100 \mathrm{ng} / \mathrm{ml}$ was $28.5 \%$, while AgNPs-43 was $64 \%$ (s 7). Small nanoparticles (10-50nm) enter cells more easy than larger ones (250nm) (Hsin, Chen et al. 2008). The high toxicity is due to the ease causing damage to the membrane, altering the lysosomal activity and increases the production of intracellular reactive oxygen species (ROS), leading to mitochondria-dependent apoptosis Liu, Wu et al. [18]. Only $1.5 \%$ of the AgNPs-31 corresponded to particles of small size $(10.5 \mathrm{~nm})$, while el $5.2 \%$ of the AgNPs-41 $22.64 \mathrm{~nm}$, this would explain its greater toxicity.

Different factors such as light, $\mathrm{pH}$, temperature and concentration of metal ions play an important role in the synthesis of nanoparticles Rai and Yadav [27]. According to the percentages of filament inhibition, it is clear that the synthesis temperature of the AgNPs significantly affects their antifungal activity. At high temperature, the kinetic energy of the molecules increases, and the silver ions are consumed faster, leaving less possibilities of growth in the size of the particles. Therefore, smaller particles of almost uniform size distribution are formed at higher temperatures Jain and Mehata [12]. Figure 3 shows the size of the AgNPs and the polydispersity, demonstrating that the increase of $20^{\circ} \mathrm{C}$ in the temperature led to the formation of AgNPs that were $14.3 \mathrm{~nm}$ smaller and a 0.017 decrease in the polydispersity index, indicating that in both temperatures the particles no were homogeneous.

The shape and size of AgNPs are directly related to the cell internalization process, which is based on endocytosis. The size range of nanoparticles small enough to pass through the bilayer of phospholipids, is from 10 to $500 \mathrm{~nm}$, our AgNPs are in this range (Kou, Sun et al. 2013; Kou, Bhutia et al. 2018). $\Omega$ is defined as the angle between the normal membrane of the cell at the junction point and the line that defines the curvature of the nanoparticle at the point of endocytosis. The particles are internalized successfully at $\Omega \leq 45^{\circ}$ and the internalization of the particles can be inhibited if $\Omega>45^{\circ}$. Studies on bacteria, yeasts, algae, crustaceans and mammalian cells have shown that the toxicity of nanoparticles depends on their shape Pal, Tak et al. [25]; Ivask, Kurvet et al. [11]; Kim, Park et al. [14]. Nanoparticles with the same surface area but with different shapes present different areas in terms of active facets. The spherical forms of AgNPs-43 were very efficient in entering yeast and therefore inhibiting filamesntation. On the other hand, rod shapes of AgNPs-31 could not be transported through the membrane, this explains the higher percentages of inhibition of AgNPs synthesized at $5^{\circ} \mathrm{C}$. The hypothesis was accepted since we observed that the AgNPs inhibit the filamentous forms and this capacity was dependent on the synthesis temperature in AgNPs.

\section{Conclusions}

The reaction temperature plays a key role in the shape and size of the nanoparticles obtained by green synthesis. Borojoa patinoi extract successfully produced two different nanoparticles, AgNPs-31, synthesized at $25^{\circ} \mathrm{C}$, with spherical shapes of $18-45 \mathrm{~nm}$ and rods $31-38$ wide by $50-75$ in length, and AgNPs-43, synthesized at $5{ }^{\circ} \mathrm{C}$, only with spherical shapes of $20.6330 \mathrm{~nm}$. The AgNPs-43 showed a greater inhibitory effect on the filamentation process of the two species of Candida albicans evaluated and significant toxicity against the cell line MES-OV CRL-3272 at 50 and $100 \mathrm{ng} / \mathrm{ml}$.

Acknowledgements The authors thank Adriana Morales for critical revision of the manuscript, and we would like to express our gratitude to Phitother Laboratories for providing the Borojoa extract.

\section{Compliance with ethical standards}

Conflict of interest The authors declare that they have no conflict of interest

Open Access This article is licensed under a Creative Commons Attribution 4.0 International License, which permits use, sharing, adaptation, distribution and reproduction in any medium or format, as long as you give appropriate credit to the original author(s) and the source, provide a link to the Creative Commons licence, and indicate if changes were made. The images or other third party material in this article are included in the article's Creative Commons licence, unless indicated otherwise in a credit line to the material. If material is not included in the article's Creative Commons licence and your intended use is not permitted by statutory regulation or exceeds the permitted use, you will need to obtain permission directly from the copyright holder. To view a copy of this licence, visit http://creativecommons .org/licenses/by/4.0/.

\section{References}

1. Ali M, Ikram M et al (2020) "Green synthesis and evaluation of n-type $\mathrm{ZnO}$ nanoparticles doped with plant extract for use as alternative antibacterials. Appl Nanosci 10(10):3787-3803

2. Arkowitz RA, Bassilana M (2019) Recent advances in understanding Candida albicans hyphal growth. F1000Res. https:// doi.org/10.12688/f1000research.18546.1

3. Bartelli TF, Bruno D et al (2018) "Whole-genome sequences and annotation of the opportunistic pathogen Candida albicans strain SC5314 grown under two different environmental conditions. Genom Announc. https://doi.org/10.1128/genom eA.01475-17

4. Chahardoli A, Karimi $\mathrm{N}$ et al (2017) Biosynthesis, characterization, antimicrobial and cytotoxic effects of silver nanoparticles using nigella arvensis seed extract. Iran J Pharm Res 16(3):1167-1175

5. Escarcega-Gonzalez CE, Garza-Cervantes JA et al (2018) In vivo antimicrobial activity of silver nanoparticles produced via a green chemistry synthesis using Acacia rigidula as a reducing and capping agent. Int J Nanomed 13:2349-2363 
6. Ghareib M, Tahon MA et al (2016) Rapid extracellular biosynthesis of silver nanoparticles by cunninghamella phaeospora culture supernatant. Iran J Pharm Res 15(4):915-924

7. Giraldo $\mathrm{Cl}$, Rengifo L et al (2004) Determinación del sexo en borojó (Borojoa patinoi, Cuatrecasas) mediante marcadores moleculares. Revista Colombiana de Biotecnología 6(2):2004

8. Gordienko MG, Palchikova VV et al (2019) Antimicrobial activity of silver salt and silver nanoparticles in different forms against microorganisms of different taxonomic groups. J Hazard Mater 378:120754

9. Hsin $\mathrm{YH}, \mathrm{Chen} \mathrm{CF}$ et al (2008) The apoptotic effect of nanosilver is mediated by a ROS- and JNK-dependent mechanism involving the mitochondrial pathway in NIH3T3 cells. Toxicol Lett 179(3):130-139

10. Hu Y, Chen $X$ et al (2018) Distinct toxicity of silver nanoparticles and silver nitrate to Daphnia magna in M4 medium and surface water. Sci Total Environ 618:838-846

11. Ivask A, Kurvet I et al (2014) Size-dependent toxicity of silver nanoparticles to bacteria, yeast, algae, crustaceans and mammalian cells in vitro. PLoS One 9(7):e102108

12. Jain S, Mehata MS (2017) Medicinal plant leaf extract and pure flavonoid mediated green synthesis of silver nanoparticles and their enhanced antibacterial property. Sci Rep 7(1):15867

13. Khatoon N, Sharma Y et al (2019) Mode of action and anti-Candida activity of Artemisia annua mediated-synthesized silver nanoparticles. J Mycol Med 29(3):201-209

14. Kim DH, Park JC et al (2017) Effect of the size and shape of silver nanoparticles on bacterial growth and metabolism by monitoring optical density and fluorescence intensity. Biotechnol Bioprocess Eng 22(2):210-217

15. Kou L, Bhutia YD et al (2018) Transporter-guided delivery of nanoparticles to improve drug permeation across cellular barriers and drug exposure to selective cell types. Front Pharm 9:27-27

16. Kou L, Sun J et al (2013) The endocytosis and intracellular fate of nanomedicines: implication for rational design. Asian J Pharm Sci 8(1):1-10

17. Lara HH, Romero-Urbina DG et al (2015) Effect of silver nanoparticles on Candida albicans biofilms: an ultrastructural study. J Nanobiotechnol 13:91

18. Liu W, Wu Y et al (2010) Impact of silver nanoparticles on human cells: effect of particle size. Nanotoxicology 4(3):319-330

19. Ma L, Su W et al (2017) Optimization for extracellular biosynthesis of silver nanoparticles by Penicillium aculeatum Su1 and their antimicrobial activity and cytotoxic effect compared with silver ions. Mater Sci Eng C Mater Biol Appl 77:963-971

20. Mathur P, Jha $S$ et al (2018) Pharmaceutical aspects of silver nanoparticles. Artif Cells Nanomed Biotechnol 46(sup1):115-126

21. Meng L, Zhao H et al (2019) Inhibition of Yeast-to-hypha transition and virulence of $<$ em $>$ Candida albicans $</$ em $>$ by 2-Alkylaminoquinoline Derivatives. Antimicrob Agents Chemother 63(4):e01891-01818

22. Nasrollahzadeh M, Mahmoudi-Gom Yek S et al (2019) Recent developments in the plant-mediated green synthesis of $\mathrm{Ag}$ based nanoparticles for environmental and catalytic applications. Chem Rec 19(12):2436-2479

23. Newton KM, Puppala HL et al (2013) Silver nanoparticle toxicity to Daphnia magna is a function of dissolved silver concentration. Environ Toxicol Chem 32(10):2356-2364

24. Odds FC, Brown AJ et al (2004) Candida albicans genome sequence: a platform for genomics in the absence of genetics. Genom Biol 5(7):230
25. Pal S, Tak YK et al (2007) Does the antibacterial activity of silver nanoparticles depend on the shape of the nanoparticle? A study of the Gram-negative bacterium Escherichia coli. Appl Environ Microbiol 73(6):1712-1720

26. Radhakrishnan VS, Reddy Mudiam MK et al (2018) Silver nanoparticles induced alterations in multiple cellular targets, which are critical for drug susceptibilities and pathogenicity in fungal pathogen (Candida albicans). Int J Nanomed 13:2647-2663

27. Rai M, Yadav A (2013) Plants as potential synthesiser of precious metal nanoparticles: progress and prospects. IET Nanobiotechnol 7(3):117-124

28. Rajeshkumar S, Bharath LV (2017) Mechanism of plant-mediated synthesis of silver nanoparticles - A review on biomolecules involved, characterisation and antibacterial activity. Chem Biol Interact 273:219-227

29. Romo JA, Pierce CG et al (2017) Development of Anti-virulence approaches for candidiasis via a novel series of small-molecule inhibitors of candida albicans filamentation. mBio. https://doi. org/10.1128/mBio.01991-17

30. Seitz F, Rosenfeldt RR et al (2015) Effects of silver nanoparticle properties, media $\mathrm{pH}$ and dissolved organic matter on toxicity to Daphnia magna. Ecotoxicol Environ Saf 111:263-270

31. Sotelo D, I., N. Casas F, et al (2010) Borojó (Borojoa patinoi): fuente de polifenoles con actividad antimicrobiana. Vitae 17:329-336

32. Souza LRR, da Silva VS et al (2018) Toxic and beneficial potential of silver nanoparticles: the two sides of the same coin. Adv Exp Med Biol 1048:251-262

33. Taha ZK, Hawar SN et al (2019) Extracellular biosynthesis of silver nanoparticles from Penicillium italicum and its antioxidant, antimicrobial and cytotoxicity activities. Biotechnol Lett 41(8-9):899-914

34. Thewes S, Moran GP et al (2008) Phenotypic screening, transcriptional profiling, and comparative genomic analysis of an invasive and non-invasive strain of Candida albicans. BMC Microbiol 8:187

35. Toenjes KA, Munsee SM et al (2005) Small-molecule inhibitors of the budded-to-hyphal-form transition in the pathogenic yeast Candida albicans. Antimicrob Agents Chemother 49(3):963-972

36. Uddin AKMR, Siddique MAB et al (2020) Cocos nucifera leaf extract mediated green synthesis of silver nanoparticles for enhanced antibacterial activity. J Inorg Organomet Polym Mater. https://doi.org/10.1007/s10904-020-01506-9

37. Wady A, Machado A et al (2012) Evaluation of Candida albicans adhesion and biofilm formation on a denture base acrylic resin containing silver nanoparticles. J Appl Microbiol 112:1163-1172

38. Wang L, Hu C et al (2017) The antimicrobial activity of nanoparticles: present situation and prospects for the future. Int J Nanomed 12:1227-1249

39. Wilkinson LJ, White RJ et al (2011) Silver and nanoparticles of silver in wound dressings: a review of efficacy and safety. J Wound Care 20(11):543-549

Publisher's Note Springer Nature remains neutral with regard to jurisdictional claims in published maps and institutional affiliations. 